\title{
Lineages of language and the diagnosis of asthma
}

\author{
Gopalakrishnan Netuveli ${ }^{1} \quad$ Brian Hurwitz ${ }^{2} \quad$ Aziz Sheikh ${ }^{3}$
}

$J$ R Soc Med 2007; 100:19-24

'We ought only to bring in a new name if it indicates a real species with distinct specific qualities; otherwise the practice is pointless. ${ }^{1}$

\section{SUMMARY}

Asthma, wheeze and cough are words with profoundly differing histories, etymologies and meanings. Yet their medical usage today is clustered around the diagnosis and management of a single disease. Hitherto, asthma has been a clinical diagnosis but wheeze, cough and asthma now are key terms in cross-cultural questionnaire surveys which seek information on asthma prevalence. In this essay, we examine differences in the linguistic properties of terms likely to be relevant to interpreting large-scale variations in asthma prevalence uncovered by questionnaires. We show how etymologically distinct each term is: while asthma and cough each share semantic congruencies across six European languages, albeit for different reasons, there is less congruence across these languages for the term wheeze. The medical meanings of all three terms contrast with meanings revealed by the non-medical usage of all three terms, which are highly figurative. Linguistic considerations indicate that interpretation of international questionnaires that phrase questions in terms of cough, asthma and their derivatives are likely to be more reliable for the purposes of comparing prevalence than those which deploy questions phrased in terms of wheeze.

\section{INTRODUCTION}

Asthma is a common label, but the trickiness of its definition and the variability in its usage have been compared with the definition and usage of a notion as complex as love. ${ }^{2}$ For most of its discernible history, asthma was used in medicine (adverbially) to qualify certain sorts of breathing difficulty. It was only in the 17 th century that 'an asthma' was viewed as a condition in its own right,

\footnotetext{
${ }^{1}$ Research Fellow, Department of Primary Care \& Social Medicine, Imperial College London, London W6 8RP; 'Professor of Medicine and the Arts, Schoo of Humanities, King's College London, London WC2R 2LS; ${ }^{3}$ Professor of Primary Care Research \& Development, Division of Community Health Sciences: GP Section, University of Edinburgh, Edinburgh EH8 9DX, Scotland, UK Correspondence to: Aziz Sheikh

E-mail: aziz.sheikh@ed.ac.uk
}

when asthma (the noun) came to be qualified with one of many possible adjectives at the time: hysterical, flatulent, convulsive, uterine, peptic, spasmodic, nervous, bronchial or cardiac asthma-aetiologies which would have been suggested by the clinical history.

Coughing, wheezing, whistling and hissing sounds associated with disordered breathing were features physicians found notable when diagnosing asthma. However, the invention of percussion in the 18 th century ${ }^{3}$ and the development of mediate auscultation with invention of the stethoscope in the 19th century ${ }^{4}$ drew physicians' attention away from the oral testimony of patients when diagnosing asthma, turning it towards the search for clinical signs. ${ }^{5}$ Until the end of the 20th century, the diagnosis of asthma was inherently clinical, dependent on close contact and exchange of information between patients and doctors. However, end of century multi-centre epidemiological studies, such as the International Study of Asthma and Allergies in Childhood (ISSAC) and the European Community Respiratory Health Survey (ECRHS), bypassed clinical exchange of information and used, instead, selfcompleted questionnaires reliant on key word descriptors to elicit information diagnostic of asthma from populations speaking different languages. ${ }^{6,7}$

Such questionnaires are predicated on the modern trend towards greater parsimony of symptom description in the medical definition of asthma and on assumed closer correspondence between certain word descriptors and underlying patho-physiological processes believed to be important in disease mechanisms in asthma (e.g. bronchoconstriction). Yet lay discussions of breathing disorders continue to evoke much more elaborate descriptions of symptoms associated with shortness of breath and laboured breathing, which are not easily or fully reducible to 'wheeze' or 'exercise induced broncho-spasm' or 'cough' ${ }^{8}$ So today, asthma is a diagnosis strongly suggested by the utterance of, or by ticking a box containing, certain key words: wheeze; whistling; difficulty breathing; cough; cough on exertion; or cough at night in bed. But do such words uttered in different languages by different discourse communities reliably label similar facts and support clinical diagnoses?

On the one hand, the meaning of terms derives, in part, from what they denote-i.e. from what they discernibly and reliably refer to; on the other hand, their meaning tends 
to change because language usage evolves, altering meanings, including the meanings of terminologies. Different words (or combinations of words) can denote the same thing, may have the same literal referent such as 'wheeze' and 'musical sounds in my chest' (of a certain frequency), which medically trained ears translate as bronchoconstriction. However, the same term used by members of different speech communities, may have quite different referents: 'shortness of breath' can refer to difficulty in breathing, to rapid breathing and/or to breathlessness, all of which describe different states of affairs (and sensations). In addition, outside of the medical context these terms tend to carry quite different metaphorical meanings.

The literal referents of some words can be more discrete than those of others. For example, 'wheeze' refers to a sound (and possibly a sensation) behaviourally and aurally much less distinct than that denoted by its rhyming sister 'sneeze'. The word 'cough', on the other hand, has a distinct though complex behavioural referent.

Critical terms for the diagnosis of asthma can be studied by tracing them back to their roots etymologically and by examining their modern use. Etymology, 'the study of the historical relation between a word and the earlier form or forms from which it has developed' ${ }^{9}$ is important to medicine because it can help explain how these terms and concepts have evolved. ${ }^{10}$ In this essay, we trace how three particular terms became medically associated, by looking at the etymology of the words in English and comparable terms in other European languages and by looking at their usage in modern English.

We used dictionaries of etymology and word origin to trace the origin of asthma, wheeze and cough, and electronic dictionaries to translate and back translate these words into other European languages (see Appendix 1). Collections of electronic editions of literary works in English were searched, and we also traced early use of the word 'asthma' in Greek using the Perseus Collection, an on-line library of classical Greek and Latin texts. ${ }^{11} \mathrm{We}$ searched Medline for articles with these terms in their title in English and in other European languages.

Because the meanings of words are constantly in flux as a result of usage, we went beyond etymology and examined social usage of these terms using linguistic resources. We searched the British National Corpus (BNC), a corpus of approximately 100 million words in English. ${ }^{12}$ We searched for 'cough', 'coughed', 'coughing', 'coughs', 'asthma', 'asthmatic', 'asthmatics', 'wheeze', 'wheezed', 'wheezing', 'wheezes', and studied in detail a random sample of 50 from each of the total number of hits for each term. Usage of each of these terms was classified as 'medical' if the word was used to denote some kind of difficulty breathing or if clearly used as a medical term, 'metaphorical' if used metaphorically and 'alternative' if used in some other way (e.g. wheeze as a clever scheme). The quotes from the BNC identify the source of each usage with an alpha-numerical identifier.

The earliest recorded use in English is that of cough (c. 1325), followed by asthma (c. 1398) and wheeze (verb c. 1460 , noun c. 1834). ${ }^{13}$

\section{COUGH}

From the Middle English coughen, the word is onomatopoetic, echoing the sound which it denotes. Johnson derived its origin from Dutch kuch, and defined it as 'a convulsion of the lungs, vellicated by some sharp serosity. ${ }^{14}$ In German and Italic languages, words with roots in Latin tuss are employed and have entered English as tussive.

\section{ASTHMA}

The word 'asthma' has a long history. Derived from the Sanskrit vayu meaning 'wind', it found its way into Greek as $\alpha^{\prime} \iota^{\prime} \omega$ (to blow), and through Latin entered Middle English as asma. The term was not originally associated with disease. Homer's use of the term 'pant' ( $\alpha \sigma \theta \mu \alpha)$ to describe extreme breathlessness of battle weary heroes - Hector after his near defeat by Ajax (Iliad, Book 15, line 241) and Ajax, himself, during his last battle with the Trojans (Iliad, Book 16, line 109) $)^{15}$ — seem to have ensured that the experiential content of laboured breathing which is denoted by panting became a semantic component of the term asthma as it evolved in European culture. In subsequent centuries the word was popularized in Greek drama as $\alpha \sigma \theta \mu \alpha \tau$ os (Aeschylus 525-456 BCE, Persians) ${ }^{16}$ and in poetry (Pindar 518438 BCE, Nemean Odes). ${ }^{17}$ Hippocrates (460-370 BCE) used the term asthma $(\dot{\alpha} \sigma \theta \mu \alpha)$ to refer to a condition of laboured breathing and noted its seasonal relation to autumn (Aphorisms, Section 3, 22) and to middle age (Aphorisms, Section 3,30$).{ }^{18}$ By the first century CE, asthma was used to describe a state of sickness, the word then referring to laboured, rapid, and putrid breathing of the afflicted Herod (Flavius Joseph, 37-100 CE, Antiquitates Judaicae). ${ }^{19}$

A more detailed treatment of asthma in ancient Greek medical literature can be found in Marketos and Ballas. ${ }^{20}$ Onians, in an extensive review of ideas about breath in European thought, points out that Greek $\alpha^{\prime} \iota^{\prime} \omega$ and $\alpha^{\prime} i \sigma \theta \omega$ refer to breathing in as a 'taking in' of some thing, as in $\alpha^{\prime} i \sigma \theta_{0} \mu \alpha l$ (or $\alpha^{\prime} \iota \sigma \theta \alpha \omega_{0} \mu \alpha l$ ), 'I perceive'. ${ }^{21}$ Asthma, or a closely related word such as asthme in French, or acma in Slavic, is in use today in each of the six modern European languages we examined, the term being used to describe a medical condition (Table 1). 
Table 1 Equivalent terms for asthma, wheeze and cough in some European languages based on searches of Medline

\begin{tabular}{|c|c|c|c|}
\hline Language & Asthma* & Wheeze $^{\dagger}$ & Cough \\
\hline French & Asthme* & Siffler ${ }^{\dagger}$ & $\begin{array}{l}\text { Toux }^{\star} \\
\text { Tousser }^{\dagger}\end{array}$ \\
\hline Spanish & Asma* $^{*}$ & $\begin{array}{l}\text { Resuello* } \\
\text { Resollar }\end{array}$ & $\begin{array}{l}\text { Tos }^{\star} \\
\text { Toser }^{\dagger}\end{array}$ \\
\hline German & Asthma* & $\begin{array}{l}\text { Keuchen }{ }^{\dagger} \text { (gasp) } \\
\text { Schnaufen (blow) }\end{array}$ & $\begin{array}{l}\text { Husten* } \\
\text { Husten }\end{array}$ \\
\hline Italian & Asma* $^{*}$ & Ansimare $^{\dagger}$ (pant) & $\begin{array}{l}\text { Tosse* } \\
\text { Tossiere }^{\star}\end{array}$ \\
\hline Portuguese & Asma* $^{*}$ & Resfolegar (putter) & $\begin{array}{l}\text { Tosse* } \\
\text { Tossir }^{\dagger}\end{array}$ \\
\hline
\end{tabular}

${ }^{*}$ Noun

†'Verb.

\section{WHEEZE}

Wheeze is derived from the Indo-European root kwes also meaning 'to pant'; it moved into Germanic as hwsjan and Old Norse as hvcesa ('to hiss') before entering Middle English as whesen. In their origins, wheeze and asthma have a similar meaning, each carrying reference to experiences of laboured breathing associated with fighting. Kwes is also the root of the Sanskrit word kAsa meaning cough and thus links wheeze etymologically with cough. Recent usage has paired wheeze with whistle (wheezing or whistling) in medical questionnaires (see Box 1), especially because whistle calls attention to the musical nature of wheeze in those languages in which wheeze has no meaning. However, the origin of whistle is quite different (Old English hwistlian and Middle English whistlen) from wheeze.

Although the term wheeze has semantic relations with the word pant, it became commonly employed to refer to a sound characterized by a frequency of some $210-280 \mathrm{~Hz},{ }^{22}$ a sound held to have a 'musical' quality. Forgacs compared the mechanism of wheeze to the production of sound by a

Box 1 Key questions from two trans-national self-completed asthma prevalence questionnaires

ISAAC

Have you ever had wheezing or whistling in the chest at any time in the past?

Have you ever had asthma?

In the past 12 months, have you had a dry cough at night, apart from a cough associated with a cold or chest infection?

\section{ECRHS}

Have you had wheezing or whistling in your chest at anytime in the last 12 months?

Have you been woken by an attack of coughing at any time in the last 12 months?

Have you had an attack of asthma in the last 12 months? toy trumpet. ${ }^{23}$ To translate the term wheeze into languages where there is no equivalent term, etymologically quite different terms such as squeaking (meaning the sound made by small animals especially rodents, from Middle English squeken, perhaps of Scandinavian origin) have been used. ${ }^{24}$

There is no term for wheeze in Dutch. Piepen, used by

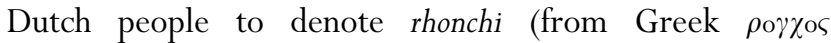
(rhoncus), snore or rattling sound), is a term used to describe squeaky sounds. German pfeifen describes sounds which in English may be translated as howl, whistle, swish, or whine. A whistling sound in French is sifflante and was used to denote what in English we call wheeze. In addition to sifflante, the verbs siler and siffler are verbs used to denote wheezing. ${ }^{25}$ Other Italic languages use various forms of Latin sibilans, sibilant-, the present participle of sibilare, meaning to hiss. Interestingly, patterns of more recent usage as found on the titles of medical papers suggest 'wheeze' and 'wheezing' are becoming nosological terms like asthma; it is now not uncommon to hear clinicians refer to 'wheezing disorders'. ${ }^{26}$

\section{USES OF COUGH, ASTHMA AND WHEEZE IN CURRENT ENGLISH}

In the BNC, cough and related words were the most frequently used of these terms, followed by asthma and wheeze (Table 2). But whereas cough, asthma and their derivatives almost always carry a medical meaning as used in the BNC, wheeze and its derivatives do so on only just over half the occasions they are used $(95 / 161=59 \%)$. All three groups of terms were used mainly in their medical sense, and asthma and its forms were almost always so used. Rarely, asthma can be used as a simile ('The vastness was closing in, choking me like asthma'27) or metaphorically (The windscreen wipers sounded asthmatic...28). We also found asthma used comically (...floundering like an asthmatic salmon ... ${ }^{29}$ ).

Like asthma, cough related terms were also predominantly used in their usual medical sense. However, the productive nature of cough has given rise to the metaphor for producing anything, especially money (Sickly Britons coughed up $£ 438$ million on health remedies last year . . $\left.{ }^{30}\right)$. The noise produced by expelling air forcefully by machinery, for example, is referred to by cough (The bus threw itself into gear, coughed, and started off noisily ${ }^{31}$ ). In an alternative sense, cough is also used to describe the sound produced to call attention, to cover up or fill in an awkward moment (Mrs Clamp... coughed politely ${ }^{32}$ ).

Wheeze, referring to a whistling sound, was used in $59 \%$ of samples and in its informal meaning of a clever trick or plan was found in 31\%. Like cough, wheezing, the sound, was also attributed to non-human sources (The wipers began to wheeze as the snowflakes built up .. $\left.{ }^{33}\right)$. With the use 
Table 2 Frequency and type of use of asthma terms in the British National Corpus

\section{Number (\%) in a random sample of 50 extracts}

\begin{tabular}{|c|c|c|c|c|}
\hline \multirow[b]{2}{*}{ Terms } & \multirow{2}{*}{$\begin{array}{l}\text { Total } \\
\text { hits }\end{array}$} & \\
\hline & & Medical & Simile/metaphor & Alternative \\
\hline Cough & 778 & $45 \quad(90)$ & $5(10)$ & $0 \quad(0)$ \\
\hline Coughed & 290 & 42 (84) & $6(12)$ & $2(4)$ \\
\hline Coughing & 390 & $50(100)$ & $0 \quad(0)$ & $0 \quad(0)$ \\
\hline Coughs & 86 & $50(100)$ & $0 \quad(0)$ & $0 \quad(0)$ \\
\hline Asthma & 651 & 49 (98) & $1 \quad(2)$ & $0 \quad(0)$ \\
\hline Asthmatic & 81 & $47 \quad(94)$ & $3(6)$ & $0 \quad(0)$ \\
\hline Asthmatics & 78 & $50(100)$ & $0 \quad(0)$ & $0 \quad(0)$ \\
\hline Wheeze & 70 & $28 \quad(56)$ & $5(10)$ & $17(34)$ \\
\hline Wheezed & 36 & $17(47)^{\star}$ & $5(14)^{\star}$ & $14(39)^{\star}$ \\
\hline Wheezing & 108 & 39 (78) & $11(22)$ & $0 \quad(0)$ \\
\hline Wheezes & 25 & 11 (44) & 3 (12) & $11(44)$ \\
\hline
\end{tabular}

*Percentages based on 36 hits

of wheeze came the metaphor of lungs as bellows, especially that of a musical instrument (Between every phrase, his lungs wheezed like broken bellows; ${ }^{34}$ Haverford. . . wheezed like a rusty concertina $\left.{ }^{35}\right)$. Reverse instances were also found, in which the metaphor of laboured breathing was applied to music (they heard a cracked wheezing, the unskilled sequence of chords of a sea-shanty played at half speed $\left.{ }^{36}\right)$.

\section{CONCLUSIONS}

Words are of central importance to medicine as most of what occurs in clinical encounters is talk. ${ }^{37}$ Words denote disease and convey experiences of it; they also influence critically the design and response to medical questionnaires. But words change their meaning in response to many pressures. Medicalization of common words (as we show, asthma was a word originally used to describe laboured breathing not a disease) may have its counterpart in the colloquialization of medical terms (wheeze being used as a surrogate for asthma in epidemiological prevalence surveys). Medical reporting often shifts from 'medical' language to 'personal' language $\mathrm{e}^{38}$ in its attempt to appropriate facets of reality that match different users' perspectives. $^{39}$

It is when perspectives may significantly differ - as they do between clinician and patient, and epidemiologist and survey participant - that language can be critical in highlighting conceptual similarities and differences. We find considerable historical and cross-cultural differences in the meanings and usages of present-day terms adopted to lexical equivalence between different European languages for key words used in the diagnosis of asthma are akin to the technique of back translation used for cross-cultural adaptation of survey questionnaires. In attempts to achieve this, certain terms are reduced to a set of alternative linguistic codes which are believed to carry the same literal referents justifying equivalence in usage. ${ }^{40,41}$

Our analysis reveals that the terms asthma and cough are almost always used with a medical meaning in the BNC and share semantic congruencies across six European languages (asthma because of Greek/Hippocratic influence and cough perhaps because of the imitative nature of its origin). Across these languages there appears to be much less congruence in the case of the term wheeze, which has had its medical meaning transformed on at least two occasions-from symptomatic of great effort (i.e. panting) to descriptive of musical sounds and, most recently, from descriptive of musical sounds to something nosological (i.e. denoting a disease entity) and in the BNC wheeze and its derivatives are used with medical meaning on only 59\% of occasions sampled. Because the medical semantic framework of wheeze is in transition questionnaire based reliance on its use for international prevalence comparisons needs to be interpreted with care.

Use of language is constantly changing as a result of creative acts expressing new thoughts and experiences. Consequentially, the meanings of words cannot be captured (or simply derived) from dictionary definitions alone, nor can their meanings be reduced (as Aristotle may have believed $)^{1}$ simply to the object(s) or performances to which they may refer-in this case to behaviours labelled panting, wheezing or coughing-because new developments in the way such words are deployed, reused and abandoned within human discourses and utterances inevitably create new meanings. As Wittgenstein indicated, naming something is not always a form of specific labelling, for when a thing is named, it does not preclude the name carrying metaphorical and other meanings within the overall 'language-game'42 which this study clearly shows.

Asthma, when used medically to denote a disease, carries a narrower range of meanings than when used nonmedically. The same is also true of wheeze and, to a lesser extent, of cough. Wheeze is clearly a term that takes on quite different meanings in differing communities of discourse, understanding of which differs between individuals and groups. ${ }^{43-45}$ While professional usage tends to harmonize overall usage, technical medical terms may well retain differing semantic associations:

'The doctors ask: does he wheeze or rattle? But you know, all these words. I think it can be difficult to distinguish. Because he never wheezes... he breathes like a bull . . he snorts.' 46 
The extent to which non-medical usages influence patient responses to questionnaires across different cultures and languages remains unknown. Lay usage of asthma terms is subject to change not least from the influences of professional discourse; increasing lay awareness of wheeze as a key medical term may alter thresholds at which people apply terms like wheeze and wheezing to all sorts of respiratory symptoms and may account in part for secular trends in asthma prevalence. ${ }^{47}$

The interpretation of questions based on use of the descriptors cough and asthma in international prevalence questionnaires may be more linguistically reliable than questions based on the term wheeze: a finding which has implications for studies such as ISAAC and ECRHS, which assume that semantic variability in their use across languages and cultures is minimal. This hypothesis is supported by the responses to the video questionnaire in ISAAC, which highlighted variability in the understanding of wheeze among the participants and the parents. ${ }^{48,49}$ Our conclusion could be tested empirically, by calling up subgroup samples of different language respondents of such trans-national studies and undertaking a linguistic study of the variance in usage of terms such as asthma, wheeze and cough, linking usages of these terms to objective measures of asthma/nonasthma status.

Acknowledgments We thank Professor John Rees, Dr Andrew Herxheimer and the anonymous reviewer for helpful comments on earlier drafts.

Competing interests AS chairs the research committee of the British Thoracic Society. GN and BH have no conflicts of interest.

Funding G Netuveli was employed on a grant from Asthma UK (Grant 01/018).

\section{APPENDIX 1}

\section{Dictionaries used}

1 Dictionary.com [http://dictionary.reference.com/ translate/text.html] Accessed 4 October 2005

2 Ectaco online dictionary [http://www.ectaco.com/ online-dictionary/] Accessed 4 October 2005

3 Eurodicautom. European terminology database [http:// europa.eu.int/eurodicautom/Controller] Accessed 4 October 2005

4 Multilingual Glossary of Technical and Popular Medical Terms in Nine European Languages [http://users. ugent.be/ $\sim$ rvdstich/eugloss/welcome.html] Accessed 4 October 2005
5 The American Heritage Dictionary of the English Language. New York: Bartleby.com, 2000 [http://www. bartleby.com/61/] Accessed 4 October 2005

6 Your Dictionary [http://www.yourdictionary.com/] Accessed 4 October 2005

\section{REFERENCES}

1 Aristotle. In: Roberts WR, transl. Rhetoric [http://classics.mit.edu/ Aristotle/rhetoric.3.iii.html] Accessed 9 August 2006

2 Gross N. What is this thing called love? Or defining asthma. Am Rev Respir Dis 1980;121:203-4

3 Auenbrugger L. Inventum novum (1761). In: Forbes J, transl. On the percussion of the chest. Bull Hist Med 1936;4:373-403

4 Laennec RTH. A Treatise on the Diseases of the Chest and On Mediate Auscultation. New York: Samuel Wood \& Sons, 1830

5 Sterne J. Mediate auscultation, the stethoscope, and the "Autopsy of the Living": medicine's acoustic culture. J Med Humanities 2001;22: $115-36$

6 The International Study of Asthma and Allergies in Childhood (ISAAC) Steering Committee. Worldwide variation in prevalence of symptoms of asthma, allergic rhinoconjunctivitis, and atopic eczema: ISAAC. Lancet 1998;351:1225-32

7 Burney PG, Luczynska C, Chinn S, Jarvis D. The European Community Respiratory Health Survey. Eur Respir J 1994;7:954-60

8 Young B, Fitch GE, Dixon-Woods M, Lambert PC, Brooke AM. Parents' accounts of wheeze and asthma related symptoms: a qualitative study. Arch Dis Child 2002;87:131-4

9 Hoad TF, ed. The Concise Oxford Dictionary of English Etymology. Oxford: Oxford University Press, 1997

10 Sharp D. Small Latin, even less Greek. Lancet 2005;366:794

11 Crane G (editor-in-chief). The Perseus Digital Library [http://www. perseus.tufts.edu] Accessed 9 September 2006

12 Oxford University Computing Services. British National Corpus [http:// www.natcorp.ox.ac.uk/] Accessed 9 August 2006

13 Oxford University Press. Oxford English Dictionary Online [http:// dictionary.oed.com $/ \mathrm{cgi} /$ entry $/ 50013687$ ? single $=1 \&$ query_type $=$ word\&queryword=asthma\&firs] Accessed 9 August 2006

14 Lynch J, ed. Samuel Johnson's Dictionary. Florida: Levenger Press, 2002

15 Homer. Homeri Opera in Five Volumes. Oxford, Oxford University Press, 1920 [http://www.perseus.tufts.edu/cgi-bin/ptext?lookup= Hom.+Il.+15.220] and [http://www.perseus.tufts.edu/cgi-bin/ ptext?lookup=Hom.+Il.+16.74] Accessed 9 August 2006

16 Aeschylus. In:Weir Smyth H, ed. Suppliant Maidens, Persians, Prometheus, and Seven Against Thebes. Cambridge: Harvard University Press [http:/ / www.perseus.tufts.edu/cgi-bin/ptext?lookup=Aesch.+Pers. +480] Accessed 9 September 2006

17 Pindar Odes [http://www.perseus.tufts.edu/cgi-bin $/$ ptext?lookup= Pind.+N.+10.1] Accessed 9 September 2006

18 Hippocrates. Aphorisms. In: Jones WHS, transl. Hippocrates Works, Vol II. Cambridge: Harvard University Press, 1967

19 Flavius Josephus. Antiquitates Judaicae. In: Niese B, ed. Flavii Ioseph Opera. Berlin: Weidmann, 1892 [http://www.perseus.tufts.edu/cgibin/ptext?lookup=J.+AJ+17.146] Accessed 9 September 2006

20 Marketos SG, Ballas NC. Bronchial asthma in the medical literature of Greek antiquity. J Asthma 1982;19:263-9

21 Onians RB. The Origins of European Thought: About the Body, the Mind, the Soul, the World, Time, and Fate; New Interpretations of Greek, Roman, and Kindred Evidence, Also of Some Basic Jewish and Christian Beliefs. Cambridge: The University Press, 1954 
22 Bueso A, Irigaray R, Romero PV. A phonogramic study of expiratory wheezing in the asthmatic patient. Arch Bronconeumo 1995; 31:501-6

23 Forgacs P. Crackles and wheezes. Lancet 1967;2:203-5

24 Pararajasingam CD, Sittampalam L, Samani P, Pattermore PK, Holgate ST. Comparison of the prevalence of asthma among Asian and European children in Southampton. Thorax 1992;313: 148-52

25 Cloutier-Beaudry G, Jeanneret-Grosjean A. Siler? Siffler? Avoir la respiration sifflante? Etude du mot siler en langage medical. Union Med Canada 1985;114:428-30

26 Editorial. A plea to abandon asthma as a disease concept. Lancet 2006;368:705

27 Howard G. Wheelbarrow Across the Sahara. Gloucester: Alan Sutton, 1990: 12-91 [AT3 2462]

28 Kelly C. The Forest of the Night. Oxford: Oxford University Press, 1991 [ACV 1801]

29 Punch. London: Punch Publications, 1992 [BNP 885]

30 The Daily Mirror. London: Mirror Group Newspapers, 1992 [CHZ 7066]

31 Chisnall E. Bell in the Tree. Edinburgh: Mainstream, 1989

32 Banks I. The Wasp Factory. London: Abacus, 1990: 7-126 [ALL 1476]

33 Deighton L. Billion-dollar Brain. London: Arrow Books, 1991: 67-219 [HR7 1416]

34 London P. Flood Water. London: Headline, 1993: 3-108 [FPM 29]

35 Mortimer J. Summer's Lease. London: Penguin, 1988: 1-155 [FB9 2207]

36 Robinson D. Goshawk Squadron. London: Fontana Press, 1993: 60-194 [HRA 238]

37 Hall JA, Roter DL. Doctors Talking With Patients/Patients Talking With Doctors: Improving Communication in Medical Visits. Westport: Auburn House, 1993
38 Poirier S, Brauner DJ. Ethics and the Daily Language of Medical Discourse. Hastings Center Rep 1988;18:5-9

39 Derrida J. Of Grammatology, Spivak GC, transl. Baltimore: Johns Hopkins University Press, 1975

40 Brown, RW. Words and Things. Glencoe: The Free Press, 1958

41 Deutscher I. Asking questions cross-culturally: some problems of linguistic comparability. In: Becker HS, Geer B, Riesman D, Weiss RS, eds. Institutions and The Person: Papers Presented To Everett C. Hughes. Chicago: Aldine, 1968: 318-41

42 Wittgenstein L. Philosophical Investigations, 3rd edn. Hemel Hempstead: Prentice Hall, 1999

43 Cane RS, Ranganathan SC, McKenzie SA. What do parents of wheezy children understand by "wheeze"? Arch Dis Child 2000;82: 327-32

44 Hardie GE, Janson S, Gold WM, Carrieri-Kohlman V, Boushey HA. Ethnic differences: word descriptors used by African-American and white asthma patients during induced bronchoconstriction. Chest 2000; 117:935-43

45 Campbell EJM, Scadding JG, Roberts RS. The concept of disease. BMJ 1979;2:757-62

46 Ostergaard MS. Childhood asthma: parent's perspective - a qualitative interview study. Fam Pract 1998;15:153-7

47 Magnus P, Jaakkola JJK. Secular trend in the occurrence of asthma among children and young adults: critical appraisal of repeated cross sectional surveys. BMJ 1997;314:1795-9

48 Crane J, Mallol J, Beasley R, Stewart A, Asher MI. Agreement between written and video questions for comparing asthma symptoms in ISAAC. Eur Respir J 2003;21:455-61

49 Cane RS, McKenzie SA. Parents' interpretation of children's respiratory symptoms on video. Arch Dis Child 2001;84: 31-4 